\title{
Measuring Eating Concerns in Black and White Adolescent Girls
}

\author{
Debra L. Franko, ${ }^{1 *}$ Ruth H. Striegel-Moore, ${ }^{2}$ Bruce A. Barton, ${ }^{3}$ \\ Barbara C. Schumann, ${ }^{3}$ David M. Garner, ${ }^{4}$ Stephen R. Daniels, ${ }^{5}$ \\ George B. Schreiber, ${ }^{6}$ and Patricia B. Crawford ${ }^{7}$ \\ ${ }^{1}$ Department of Counseling and Applied Educational Psychology, \\ Northeastern University, Boston, Massachusetts \\ ${ }^{2}$ Department of Psychology, Wesleyan University, Middletown, Connecticut \\ ${ }^{3}$ Maryland Medical Research Institute, Baltimore, Maryland \\ ${ }^{4}$ River Centre Clinic, Toledo, Ohio \\ ${ }^{5}$ Division of Cardiology, Department of Pediatrics, University of Cincinnati College \\ of Medicine and the Children's Hospital Medical Center, Cincinnati, Ohio \\ ${ }^{6}$ Westat, Inc., Rockville, Maryland \\ ${ }^{7}$ Center for Weight and Health, University of California at Berkeley, Berkeley, \\ California
}

Accepted 8 February 2003

\begin{abstract}
Objective: Few instruments exist to measure eating concerns in adolescent girls from diverse ethnic backgrounds. Methods: A Children's version of the Eating Disorder Inventory (EDI-C) has been under development for several years and was designed to be more appropriate for younger children with lower reading levels. However, little is known about the validity of this instrument. The current study reports on the factor structure of an early version of the EDI-C using nonclinical samples of 1,073 White and 1,155 Black girls (ages 11-12). Results: Factor analysis resulted in an eight-factor solution for each group that included a weight concerns factor and an emotional distress factor. For Black girls only, the positively worded items from the Body Dissatisfaction subscale loaded on a separate factor. Four of five factors were similar to the original EDI subscales (Bulimia, Interpersonal Distrust, Maturity Fears, and Perfectionism), although the latter was unique to White girls. Discussion: The factor structure was generally similar for Black and White girls, although the separate body satisfaction factor and lack of shared variance for the perfectionism factor for Black girls suggest that EDI data obtained from ethnic minority samples may need to be interpreted cautiously. (C) 2004 by Wiley Periodicals, Inc. Int J Eat Disord 35: 179-189, 2004.
\end{abstract}

Key words: eating concerns; Black girls; White girls; Eating Disorders Inventory

Portions of this manuscript were presented at the 2002 International Conference on Eating Disorders, Boston, Massachusetts.

*Correspondence to: Debra L. Franko, Ph.D., Department of Counseling and Applied Educational Psychology,

Northeastern University, 203 Lake Hall, Boston, MA 02115-5000. E-mail: d.franko@neu.edu

Published online in Wiley InterScience (www.interscience.wiley.com). DOI: 10.1002/eat.10251

(C) 2004 by Wiley Periodicals, Inc. 


\section{INTRODUCTION}

The Eating Disorder Inventory (EDI) is a self-report instrument that assesses the cognitive and behavioral characteristics commonly found in individuals with anorexia nervosa and bulimia nervosa (Garner, 1991; Garner, Olmsted, \& Polivy, 1983). Although initially developed for use in clinical samples, the EDI is used widely with nonclinical subjects. The original 64-item EDI (Garner et al., 1983) comprised eight subscales (Drive for Thinness [DT], Bulimia [B], Body Dissatisfaction [BD], Ineffectiveness [I], Perfectionism [P], Interpersonal Distrust [ID], Interoceptive Awareness [IA], and Maturity Fears [MF]). Examinations of the psychometric properties of the EDI have found it to be a reliable and valid instrument (Eberenz \& Gleaves, 1994). Most factor analytic studies conducted on the EDI with clinical samples have provided support for the eight-factor structure for the 64-item version of the original instrument (Eberenz \& Gleaves, 1994; Raciti \& Norcross, 1987; Welch, Hall, \& Walkey, 1988). However, Schaefer, Maclennan, Yaholnitsky-Smith, and Stover (1998) found only five factors using a small sample $(n=$ 79) of outpatients. In contrast, fewer factors have generally been found when the EDI has been administered to nonclinical samples (Bennett \& Stevens, 1997; Phelps \& Wilczenski, 1993; Welch et al., 1988). In nonclinical samples, the EDI factors seem to separate into those measuring core eating pathology (e.g., body dissatisfaction, bulimic behaviors) and those associated more with psychological factors (e.g., perfectionism, interpersonal distrust). Joiner and Heatherton (1998) examined the factor structure of five EDI scales in a relatively large college student sample tested twice (10 years apart) and found support for the intended factor structure for these five subscales (DT, B, P, ID, and MF). However, it should be noted that the number of items included influences the results of factor analytic studies, suggesting that a different result may have been obtained had all EDI items been administered.

Although the standardization groups for the EDI were college-aged women (mean age for the patient group $=23.3$ years; mean age for the female comparison group $=19.9$ years), the EDI is often used with young and middle adolescent samples (Engelsen \& Laberg, 2001; Simmons, Smith, \& Hill, 2002) because this is the time of greatest risk for the development of eating disorders (Ohring, Graber, \& Brooks-Gunn, 2002). However, caution must be used in generalizing data derived from older clinical samples to younger nonclinical samples. First, younger and older adolescents score differently on EDI subscales. Therefore, age-appropriate psychometric data should be used when studying varying age groups (Shore \& Porter, 1990). Second, the factor structure of the EDI may be different for younger and older adolescents. Phelps and Wilczenski (1993) conducted a factor analysis of the EDI in a nonclinical adolescent sample and reported that a threefactor solution was the most meaningful. Third, the reading level required to complete the original instrument may be too complex for some younger adolescents. Finally, the wording for some of the original EDI items is inappropriate for children because they are intended to be interpreted from the adult perspective looking back on childhood (e.g., "I wish that I could return to the security of childhood.").

A growing interest in ethnicity and eating disorders has resulted in questions regarding relative risks across ethnic groups (for review, see Smolak \& Striegel-Moore, 2001). The EDI is widely used in research with ethnic minority subjects (Abrams, Allen, \& Gray, 1993; Harris, 1995; Tsai \& Gray, 2000). To our knowledge, few studies of the psychometric properties of the EDI have been conducted in other than White adolescent samples (Boyadjieva \& Steinhausen, 1996; Leung, Wang, \& Tang, in press). If the EDI is to be used with ethnically diverse populations to better understand varying degrees of risk 
(Al-Subaie, 2000; Morande, Celada, \& Casas, 1999; Rhea, 1999), researchers must be clear that it is measuring the same constructs in diverse groups. The current study provides data on the internal consistency and factor structure of a preliminary children's version of the EDI (EDI-C) ${ }^{1}$ in a large cohort of Black and White adolescent girls for this purpose.

The current study was conducted on a large sample of Black and White adolescent girls in the National Heart, Lung, and Blood Institute Growth and Health Study (NGHS), which is a longitudinal cohort study that was designed originally to examine risk factors for obesity and cardiovascular disease. The complete EDI-C was administered to the entire sample in Years 3 and 5 when the subjects were ages 11-12 and 13-14 years old, respectively. Data from Year 3 are reported in the current study.

\section{METHOD}

Details of the NGHS design and sample characteristics have been reported elsewhere (National Heart, Lung and Blood Institute Growth and Health Study, 1992). This multicenter, longitudinal study started in 1987 with a cohort of 2,379 Black and White girls who were studied annually over 10 years at three study sites (University of California at Berkeley, Berkeley, CA; University of Cincinnati and Children's Hospital Medical Center, Cincinnati, $\mathrm{OH}$; and Westat, Inc., Rockville, MD, in association with a Washington, DC, health maintenance organization [HMO]). Maryland Medical Research Institute (Baltimore, MD) served as the coordinating center for the study.

\section{Participants}

At baseline, 1,213 Black girls (539 were 9 years old and 674 were 10 years old) and 1,166 White girls (616 were 9 years old and 550 were 10 years old) were recruited at three study sites. Eligibility criteria included the following: (1) child and parents were required to be either White or Black (racial concordance of parents and child was required); (2) girls were to be within 2 weeks of age 9 or 10 years; (3) child assent was required; and (4) parental consent and a completed household demographic sheet were also required. The University of California at Berkeley recruited participants from public and parochial schools in the Richmond Unified School District (chosen based on census tract data). The Children's Hospital Medical Center recruited participants from public and parochial schools chosen to be representative of Hamilton County, which includes inner city, urban, and suburban areas. Westat participants were drawn randomly from the membership directory of families with ageeligible girls enrolled in a large Washington, DC, area HMO. Because the GHA (Group Health Association) did not have enough eligible families with 9 or 10-year-old White girls, recruitment was extended to a group of Girl Scout troops within the geographic area of a predominantly white GHA clinic participating in the study. At Visit 3, the time of the current study, the sample size included 1,155 Black girls and 1,073 White girls.

\section{Instruments and Procedure}

The cohort was assessed annually at each site or, if the girl was unable to travel to the site, at home. A standard protocol was used across all centers and standard probes

\footnotetext{
${ }^{1}$ The Original EDI and the current form of the Children's version of the EDI (EDI-C) are available from Psychological Assessment Resources, Inc., P.O. Box 998, Odessa, FL 33556.
} 
were used to clarify incomplete responses. Participants provided information on eating patterns and dietary intake, physical activity, health beliefs and attitudes, and a range of psychosocial variables. In Year 3 of the study, self-report instruments were read to the participants by the interviewers to ensure comprehension of the questions.

\section{EDI-C}

The original EDI (Garner et al., 1983) is a 64-item self-report instrument that measures psychological and behavioral traits common in individuals with an eating disorder. It is organized into eight subscales that contain varying numbers of items (e.g., DT [7], B [7], BD [9], I [10], P [6], ID [7], IA [10], and MF [8]). Extensive data regarding reliability and validity have been reported (Eberenz \& Gleaves, 1994). For the current study, a preliminary version of the EDI-C was developed in consultation with one of the original authors of the EDI (D.M.G.) and involved simplifying and changing the wording of certain items. On this version of the EDI-C, 16 items were identical to the original EDI, 29 items were slightly reworded, and the remaining items were changed significantly from the current version of the EDI-C. On the original EDI and on the version used in the NGHS, respondents are instructed to answer the items on a 6-point Likert scale (always, usually, often, sometimes, rarely, and never). For scoring purposes, responses are weighted from 3 to 0 , such that items responded to with sometimes, rarely, or never receive a score of 0 (Garner et al., 1983).

\section{Data Analysis}

A principal components analysis (PCA) using oblique rotation (promax) was performed to determine the factor structure of the EDI for Black and White girls. Oblique rotation was selected because it appeared to have fewer cross-loadings of variables on more than one factor than the varimax rotation. The analysis was restricted to eight factors, based on the original eight EDI subscales. For this analysis, loadings greater than 0.35 were considered meaningful or significant (Hatcher, 1994).

\section{RESULTS}

The eight-factor solution accounted for $47.4 \%$ and $41.4 \%$ of the variance in the White and Black girls, respectively. Tables 1 and 2 provide the factor loadings for all items on the original eight EDI subscales for Black and White girls. Five of the eight factors extracted in separate factor analyses of the data for the Black and the White samples were similar for the two groups, although each factor contained several items that were unique to each group. The first factor was termed a weight concerns factor, as it contained items from the DT, BD, and B subscales. The second factor, emotional distress, was a compilation of items primarily from the I, ID, IA, and MF subscales. The remaining three factors that were similar for Black and White girls closely matched three of the original EDI subscales (B, ID, and MF). Two factors comprised items from two or more subscales and did not show much consistency between the Black and White participants.

Interestingly, two factors were unique to each ethnic group. For Black girls, a factor was found that consisted of five positively worded items from the BD subscale. No comparable factor was found for White girls. An additional factor comprised three items from the P subscale and one item from the ID subscale and was found only for White girls. 
Table 1. Factor loadings for an eight-factor solution with the original 64 EDI items for Black girls

\begin{tabular}{|c|c|c|c|c|c|c|c|c|}
\hline \multirow[b]{2}{*}{ Original EDI Item Number } & \multicolumn{8}{|c|}{ Factor Loadings } \\
\hline & 1 & 2 & 3 & 4 & 5 & 6 & 7 & 8 \\
\hline \multicolumn{9}{|l|}{ Drive for Thinness } \\
\hline 1 & 0.37 & 0.12 & 0.09 & -0.15 & -0.1 & 0.04 & 0.05 & 0.35 \\
\hline 7 & 0.73 & 0.08 & -0.04 & 0.18 & -0.01 & -0.03 & -0.1 & 0.01 \\
\hline 11 & 0.51 & 0.23 & 0 & -0.13 & -0.08 & 0.07 & -0.08 & -0.2 \\
\hline 16 & 0.69 & 0.12 & -0.07 & -0.09 & -0.03 & 0 & 0.05 & -0.08 \\
\hline 25 & 0.53 & 0.01 & 0.03 & 0.04 & -0.05 & 0.08 & 0.08 & 0.12 \\
\hline 32 & 0.70 & 0.07 & -0.16 & 0.2 & -0.04 & -0.03 & 0.03 & 0.07 \\
\hline 49 & 0.61 & -0.03 & 0.01 & 0.06 & 0.07 & 0 & 0.13 & 0.06 \\
\hline \multicolumn{9}{|l|}{ Body Dissatisfaction } \\
\hline 2 & 0.66 & 0.05 & -0.05 & 0.23 & -0.02 & 0.01 & 0.01 & -0.03 \\
\hline 9 & 0.71 & -0.01 & 0.02 & 0.23 & -0.03 & -0.01 & -0.14 & 0.12 \\
\hline 12 & 0.48 & -0.12 & -0.09 & 0.52 & 0.03 & 0.02 & 0.04 & -0.01 \\
\hline 19 & 0.24 & -0.05 & 0.04 & 0.64 & 0.1 & 0.06 & 0.07 & -0.02 \\
\hline 31 & 0.05 & 0.12 & 0.03 & 0.55 & 0.13 & 0.09 & 0.01 & -0.01 \\
\hline 45 & 0.67 & 0.02 & 0 & 0.24 & -0.01 & -0.06 & -0.06 & 0.04 \\
\hline 55 & 0.3 & -0.06 & 0.05 & 0.66 & -0.01 & -0.08 & -0.09 & 0.01 \\
\hline 59 & 0.28 & 0.04 & 0.16 & 0.31 & -0.07 & 0.02 & 0.1 & 0 \\
\hline 62 & 0.24 & -0.05 & 0.04 & 0.69 & 0.02 & 0.02 & 0.01 & 0.04 \\
\hline \multicolumn{9}{|l|}{ Bulimia } \\
\hline 4 & -0.1 & 0.2 & 0.59 & 0.03 & 0.02 & -0.04 & -0.17 & -0.03 \\
\hline 5 & -0.07 & -0.06 & 0.72 & 0.11 & -0.01 & 0.08 & -0.06 & -0.05 \\
\hline 28 & 0.12 & 0.03 & 0.61 & 0.03 & -0.04 & 0.02 & 0.07 & -0.09 \\
\hline 38 & -0.13 & 0.02 & 0.78 & 0.07 & -0.06 & 0.02 & -0.07 & 0.02 \\
\hline 46 & 0.02 & -0.03 & 0.67 & -0.04 & -0.01 & 0.02 & 0.07 & -0.11 \\
\hline 53 & 0.35 & 0.14 & 0.13 & 0.01 & -0.03 & -0.1 & 0.09 & -0.06 \\
\hline 61 & -0.06 & 0.15 & 0.47 & 0.05 & -0.06 & 0.04 & 0.01 & -0.03 \\
\hline 64 & 0.16 & 0.16 & 0.46 & -0.08 & 0.02 & -0.01 & -0.09 & -0.02 \\
\hline \multicolumn{9}{|l|}{ Ineffectiveness } \\
\hline 10 & -0.02 & 0.55 & -0.05 & 0.13 & -0.06 & -0.04 & 0.15 & -0.09 \\
\hline 18 & 0.02 & 0.6 & -0.01 & 0 & -0.01 & -0.07 & 0.04 & -0.13 \\
\hline 20 & -0.06 & 0.05 & 0 & 0.29 & 0.3 & 0.24 & 0.17 & -0.18 \\
\hline 24 & 0.05 & 0.46 & -0.03 & 0.16 & 0.1 & -0.17 & 0.04 & -0.02 \\
\hline 27 & -0.05 & 0.47 & 0.03 & 0.11 & -0.02 & -0.01 & 0.21 & 0 \\
\hline 37 & -0.03 & 0.03 & 0.07 & 0.34 & 0.25 & 0.04 & 0.06 & -0.22 \\
\hline 41 & -0.13 & 0.21 & -0.17 & 0.16 & -0.07 & 0.07 & 0.56 & -0.05 \\
\hline 42 & -0.14 & 0.15 & -0.11 & 0.06 & 0.29 & -0.06 & 0.07 & -0.33 \\
\hline 50 & 0.07 & 0.08 & 0.09 & 0.14 & 0.21 & -0.06 & 0.09 & -0.45 \\
\hline 56 & -0.03 & 0.33 & 0.25 & 0.07 & -0.07 & -0.11 & 0.27 & -0.08 \\
\hline \multicolumn{9}{|l|}{ Perfectionism } \\
\hline 13 & 0.24 & -0.14 & 0.16 & -0.26 & 0.21 & -0.09 & 0.2 & 0.01 \\
\hline 29 & -0.01 & 0.17 & -0.02 & -0.04 & -0.04 & 0.15 & 0 & 0.52 \\
\hline 36 & 0.2 & 0.24 & 0.13 & -0.06 & 0.02 & -0.06 & 0.07 & 0.11 \\
\hline 43 & 0.05 & -0.03 & 0.05 & -0.05 & 0.18 & -0.08 & 0.32 & 0.36 \\
\hline 52 & 0.12 & -0.01 & 0.13 & -0.18 & 0.15 & -0.04 & 0.4 & 0.11 \\
\hline 63 & 0 & 0.04 & -0.18 & 0.04 & -0.05 & 0.02 & 0.14 & 0.55 \\
\hline \multicolumn{9}{|l|}{ Interpersonal Distrust } \\
\hline 15 & -0.04 & -0.09 & 0.03 & 0.06 & 0.65 & -0.04 & -0.14 & 0.14 \\
\hline 17 & -0.1 & 0.02 & -0.01 & 0.07 & 0.48 & 0 & 0.05 & -0.08 \\
\hline 23 & 0 & 0.1 & -0.03 & 0.06 & 0.57 & 0.02 & -0.08 & -0.23 \\
\hline 30 & 0.12 & -0.08 & -0.01 & -0.15 & 0.25 & 0 & 0.14 & 0.49 \\
\hline 34 & 0.05 & 0.64 & -0.05 & -0.01 & 0.26 & -0.09 & -0.15 & 0.15 \\
\hline 54 & 0.02 & 0.03 & -0.09 & -0.01 & -0.05 & -0.06 & 0.65 & -0.08 \\
\hline 57 & 0.03 & 0.02 & -0.06 & 0.05 & 0.63 & 0.02 & -0.18 & -0.02 \\
\hline \multicolumn{9}{|l|}{ Interoceptive Awareness } \\
\hline 8 & 0.26 & 0.48 & 0.08 & -0.03 & -0.06 & 0 & -0.13 & -0.02 \\
\hline 21 & 0.04 & 0.6 & 0.03 & -0.06 & -0.08 & -0.05 & 0.04 & -0.01 \\
\hline 26 & -0.07 & -0.06 & -0.05 & 0.01 & 0.51 & 0.1 & 0.11 & -0.23 \\
\hline
\end{tabular}


Table 1. Continued

\begin{tabular}{|c|c|c|c|c|c|c|c|c|}
\hline \multirow[b]{2}{*}{ Original EDI Item Number } & \multicolumn{8}{|c|}{ Factor Loadings } \\
\hline & 1 & 2 & 3 & 4 & 5 & 6 & 7 & 8 \\
\hline 33 & -0.04 & 0.43 & -0.02 & 0.11 & -0.18 & 0.01 & 0.25 & 0.14 \\
\hline 40 & -0.05 & -0.05 & -0.01 & 0.08 & -0.12 & 0.07 & 0.62 & 0.02 \\
\hline 44 & 0.01 & 0.52 & 0.15 & -0.02 & 0.01 & -0.08 & 0.07 & 0.11 \\
\hline 47 & 0.25 & -0.06 & 0.11 & -0.21 & 0.05 & 0.11 & 0.33 & 0.04 \\
\hline 51 & 0.07 & 0.38 & 0.15 & -0.03 & 0.03 & -0.04 & 0.17 & 0.08 \\
\hline 60 & -0.02 & 0.6 & 0.08 & 0.11 & 0.04 & 0.01 & -0.05 & 0.21 \\
\hline 64 & 0.16 & 0.16 & 0.46 & -0.08 & 0.02 & -0.01 & -0.09 & -0.02 \\
\hline \multicolumn{9}{|l|}{ Maturity Fears } \\
\hline 3 & -0.01 & 0.57 & 0.04 & -0.08 & -0.02 & 0.15 & -0.1 & 0.05 \\
\hline 6 & 0.14 & 0.62 & -0.09 & -0.21 & 0.06 & 0.14 & -0.23 & -0.15 \\
\hline 14 & 0.06 & 0.17 & -0.02 & -0.1 & 0.02 & 0.43 & 0.15 & 0.22 \\
\hline 22 & -0.05 & -0.08 & 0.02 & 0.04 & 0.04 & 0.74 & -0.01 & 0 \\
\hline 35 & 0.1 & 0.56 & 0.04 & -0.08 & 0.06 & 0.21 & -0.03 & 0.07 \\
\hline 39 & -0.04 & 0.11 & 0.14 & -0.04 & 0.07 & -0.55 & 0.19 & 0.07 \\
\hline 48 & 0.06 & 0.1 & 0.07 & -0.03 & -0.02 & 0.65 & 0.18 & 0.19 \\
\hline 58 & -0.06 & -0.02 & 0.08 & 0.16 & 0.08 & 0.71 & -0.03 & 0.01 \\
\hline
\end{tabular}

Note: EDI = Eating Disorders Inventory.

The internal consistency of the factors was assessed using cronbach's alpha (Cronbach, 1951). In general, the coefficients were good for the first three factors (.76-.93) and for the body satisfaction factor in Black girls (.80). However, the internal consistency of the remaining factors was low to moderate (.15-.53). Table 3 provides the alphas for Black and White girls for all factors found in the factor analysis, including the two unique to each group. For completeness, we also provide the coefficient alphas for Black and White girls on the eight original EDI subscales, which were found to be acceptable (.50-.91) and were generally higher than those found in the factor analysis (Table 4).

Table 2. Factor loadings for an eight-factor solution with the original 64 EDI items for White girls

\begin{tabular}{|c|c|c|c|c|c|c|c|c|}
\hline \multirow[b]{2}{*}{ Orginal EDI } & \multicolumn{8}{|c|}{ Factor Loadings } \\
\hline & 1 & 2 & 3 & 4 & 5 & 6 & 7 & 8 \\
\hline \multicolumn{9}{|c|}{ Drive for Thinness } \\
\hline 1 & 0.29 & 0.35 & 0.02 & 0.07 & 0.01 & 0.1 & 0.07 & 0.26 \\
\hline 7 & 0.74 & 0.16 & 0.01 & 0.12 & 0.09 & 0.03 & 0.04 & 0.03 \\
\hline 11 & 0.41 & 0.31 & 0.11 & 0.13 & 0 & 0.1 & 0.03 & 0.19 \\
\hline 16 & 0.6 & 0.3 & 0.04 & 0.13 & 0.07 & 0.01 & 0.04 & 0.09 \\
\hline 25 & 0.64 & 0.08 & 0.01 & 0.06 & 0.03 & 0.12 & 0.02 & 0.06 \\
\hline 32 & 0.73 & 0.19 & 0.06 & 0.06 & 0.01 & 0.05 & 0.02 & 0.06 \\
\hline 49 & 0.5 & 0.12 & 0.13 & 0.04 & 0.03 & 0.23 & 0.09 & 0.04 \\
\hline \multicolumn{9}{|c|}{ Body Dissatisfaction } \\
\hline 2 & 0.78 & 0.07 & 0.01 & 0.03 & 0 & 0.07 & 0.04 & 0.03 \\
\hline 9 & 0.78 & 0.04 & 0.03 & 0.11 & 0.1 & 0.06 & 0.08 & 0.04 \\
\hline 12 & 0.77 & 0.08 & 0.05 & 0.18 & 0.06 & 0.08 & 0.01 & 0.02 \\
\hline 19 & 0.75 & 0.06 & 0.03 & 0.26 & 0.07 & 0.09 & 0.03 & 0.05 \\
\hline 31 & 0.61 & 0.12 & 0.01 & 0.24 & 0.01 & 0.02 & 0.03 & 0.13 \\
\hline 45 & 0.74 & 0.04 & 0.04 & 0.01 & 0.04 & 0.12 & 0.02 & 0.05 \\
\hline 55 & 0.81 & 0.15 & 0.05 & 0.16 & 0.02 & 0.09 & 0.06 & 0.05 \\
\hline 59 & 0.69 & 0.07 & 0.07 & 0.01 & 0.06 & 0.06 & 0.02 & 0.04 \\
\hline 62 & 0.81 & 0.15 & 0.04 & 0.17 & 0.01 & 0.07 & 0.02 & 0.05 \\
\hline
\end{tabular}


Table 2. Continued

\begin{tabular}{|c|c|c|c|c|c|c|c|c|}
\hline \multirow[b]{2}{*}{ Orginal EDI } & \multicolumn{8}{|c|}{ Factor Loadings } \\
\hline & 1 & 2 & 3 & 4 & 5 & 6 & 7 & 8 \\
\hline \multicolumn{9}{|l|}{ Bulimia } \\
\hline 4 & 0.02 & 0.29 & 0.57 & 0.04 & 0.04 & 0.31 & 0.04 & 0.03 \\
\hline 5 & 0.05 & 0.02 & 0.8 & 0.1 & 0.04 & 0.28 & 0.01 & 0.03 \\
\hline 28 & 0.1 & 0.01 & 0.7 & 0.06 & 0.03 & 0.05 & 0 & 0.06 \\
\hline 38 & 0.01 & 0.02 & 0.71 & 0.07 & 0.09 & 0.08 & 0.01 & 0.04 \\
\hline 46 & 0.02 & 0.11 & 0.66 & 0.04 & 0.02 & 0.26 & 0.07 & 0.07 \\
\hline 53 & 0.1 & 0.04 & 0.11 & 0.04 & 0.04 & 0.44 & 0.07 & 0.14 \\
\hline 61 & 0.02 & 0.03 & 0.43 & 0.08 & 0.01 & 0.28 & 0.05 & 0.03 \\
\hline 64 & 0.12 & 0.22 & 0.32 & 0.07 & 0 & 0.05 & 0.06 & 0.16 \\
\hline \multicolumn{9}{|c|}{ Ineffectiveness } \\
\hline 10 & 0.03 & 0.61 & 0.04 & 0.11 & 0.02 & 0.16 & 0.03 & 0.08 \\
\hline 18 & 0.1 & 0.55 & 0.07 & 0.12 & 0.01 & 0.03 & 0.09 & 0.2 \\
\hline 20 & 0.05 & 0.24 & 0.1 & 0.48 & 0.13 & 0.04 & 0.17 & 0.11 \\
\hline 24 & 0.11 & 0.32 & 0.01 & 0.26 & 0.08 & 0.11 & 0.14 & 0.21 \\
\hline 27 & 0.03 & 0.47 & 0.13 & 0.19 & 0.05 & 0.11 & 0.05 & 0.08 \\
\hline 37 & 0.34 & 0.08 & 0.03 & 0.54 & 0.04 & 0 & 0.04 & 0.02 \\
\hline 41 & 0.11 & 0.19 & 0.05 & 0.25 & 0.13 & 0.5 & 0.04 & 0.01 \\
\hline 42 & 0.08 & 0.05 & 0.06 & 0.5 & 0.23 & 0 & 0.07 & 0.05 \\
\hline 50 & 0.04 & 0.11 & 0.02 & 0.63 & 0.06 & 0.22 & 0.03 & 0.09 \\
\hline 56 & 0.13 & 0.33 & 0.12 & 0.16 & 0.15 & 0.32 & 0.05 & 0.19 \\
\hline \multicolumn{9}{|l|}{ Perfectionism } \\
\hline 13 & 0.01 & 0.04 & 0.11 & 0.1 & 0.04 & 0.08 & 0.08 & 0.57 \\
\hline 29 & 0.04 & 0 & 0.13 & 0.48 & 0.05 & 0 & 0.1 & 0.33 \\
\hline 36 & 0.09 & 0.37 & 0.03 & 0.19 & 0.09 & 0.07 & 0.03 & 0.27 \\
\hline 43 & 0.02 & 0.08 & 0.03 & 0.24 & 0.01 & 0.03 & 0.06 & 0.59 \\
\hline 52 & 0.06 & 0.17 & 0.04 & 0.14 & 0.05 & 0.26 & 0.03 & 0.48 \\
\hline 63 & 0.08 & 0.02 & 0.2 & 0.55 & 0 & 0 & 0.08 & 0.37 \\
\hline \multicolumn{9}{|c|}{ Interpersonal Distrust } \\
\hline $15^{1}$ & 0 & 0.09 & 0.02 & 0.08 & 0.73 & 0.11 & 0.04 & 0 \\
\hline 17 & 0.01 & 0.2 & 0.01 & 0.21 & 0.46 & 0.36 & 0.01 & 0.05 \\
\hline 23 & 0.05 & 0.12 & 0.07 & 0.2 & 0.6 & 0.04 & 0.05 & 0.05 \\
\hline 30 & 0.02 & 0.1 & 0.02 & 0.08 & 0.11 & 0.03 & 0.13 & 0.44 \\
\hline 34 & 0 & 0.6 & 0 & 0.16 & 0.45 & 0.1 & 0.06 & 0.01 \\
\hline 54 & 0.1 & 0.06 & 0.08 & 0 & 0.16 & 0.62 & 0.03 & 0.03 \\
\hline 57 & 0.01 & 0.03 & 0.02 & 0.04 & 0.74 & 0.01 & 0.01 & 0.06 \\
\hline \multicolumn{9}{|c|}{ Interoceptive Awareness } \\
\hline 8 & 0.07 & 0.69 & 0.05 & 0.04 & 0.03 & 0.1 & 0.08 & 0.04 \\
\hline 21 & 0.07 & 0.75 & 0.04 & 0.06 & 0.13 & 0.04 & 0.08 & 0.09 \\
\hline 26 & 0.09 & 0.07 & 0.04 & 0.28 & 0.3 & 0.02 & 0.08 & 0.05 \\
\hline 33 & 0.02 & 0.51 & 0.03 & 0.01 & 0.04 & 0.21 & 0.04 & 0.1 \\
\hline 40 & 0.07 & 0.36 & 0.08 & 0.01 & 0.08 & 0.31 & 0.04 & 0.18 \\
\hline 44 & 0.03 & 0.68 & 0.01 & 0.05 & 0 & 0.08 & 0.08 & 0.05 \\
\hline 47 & 0.03 & 0.09 & 0.03 & 0.04 & 0.05 & 0.5 & 0.21 & 0.09 \\
\hline 51 & 0.03 & 0.64 & 0.05 & 0.02 & 0.03 & 0.14 & 0.03 & 0.05 \\
\hline 60 & 0.01 & 0.73 & 0.02 & 0.1 & 0.06 & 0.02 & 0.06 & 0 \\
\hline 64 & 0.19 & 0.22 & 0.32 & 0.07 & 0 & 0.05 & 0.06 & 0.16 \\
\hline \multicolumn{9}{|c|}{ Maturity Fears } \\
\hline 3 & 0.04 & 0.71 & 0.17 & 0.03 & 0.07 & 0.05 & 0.06 & 0.05 \\
\hline 6 & 0.02 & 0.57 & 0.03 & 0.12 & 0.03 & 0.13 & 0.19 & 0.05 \\
\hline 14 & 0.04 & 0.2 & 0 & 0.02 & 0.12 & 0.2 & 0.56 & 0.04 \\
\hline 22 & 0.07 & 0.12 & 0.04 & 0.01 & 0.01 & 0.05 & 0.69 & 0.04 \\
\hline 35 & 0.01 & 0.6 & 0.06 & 0.03 & 0.08 & 0.09 & 0.19 & 0.05 \\
\hline 39 & 0.01 & 0.17 & 0.05 & 0.06 & 0.15 & 0.15 & 0.44 & 0.22 \\
\hline 48 & 0 & 0.88 & 0.07 & 0.09 & 0.03 & 0.15 & 0.71 & 0.13 \\
\hline 58 & 0.01 & 0.01 & 0.03 & 0.12 & 0.1 & 0.13 & 0.7 & 0.07 \\
\hline
\end{tabular}

Note: EDI = Eating Disorders Inventory. 
Table 3. Estimates of internal consistency for EDI factors for White and Black girls (Cronbach alphas)

\begin{tabular}{|c|c|c|c|}
\hline Factors & Factor Name & White Girls & Black Grils \\
\hline 1 & Weight concerns & .93 & .87 \\
\hline 2 & Emotional distress & .89 & .85 \\
\hline 3 & Bulimia & .75 & .76 \\
\hline 4 & $\begin{array}{l}\text { Mixed Ineffectiveness } \\
\text { and Perfectionism }\end{array}$ & .25 & .15 (Black Factor 8) \\
\hline 5 & Interpersonal Distrust & .68 & .62 \\
\hline 6 & $\begin{array}{l}\text { Mixed Interpersonal Distrust, } \\
\text { Interoceptive Awareness and } \\
\text { Ineffectiveness }\end{array}$ & .53 & .50 (Black Factor 7) \\
\hline 7 & Maturity Fears & .46 & .37 (Black Factor 6) \\
\hline $8^{\mathrm{a}}$ & Perfectionism & .46 & - \\
\hline $8 \mathrm{~A}^{\mathrm{b}}$ & Body satisfaction & - & .80 (Black Factor 4$)$ \\
\hline
\end{tabular}

Note: EDI = Eating Disorder Inventory.

${ }^{\mathrm{a}}$ White girls only.

${ }^{\mathrm{b}}$ Black girls only.

\section{DISCUSSION}

Overall, the EDI showed remarkable similarity for Black and White young adolescent girls. There was significant overlap between the two groups on five of eight factors. Two factors, perfectionism for White girls and body satisfaction for Black girls, were unique to each group. However, only three factors (bulimia, interpersonal distrust, and maturity fears) in the current factor analysis were found to correspond to the original EDI subscales (B, ID, MF) for both Black and White girls, suggesting that different factor structures may exist for adolescents at this age or that there may be differences between clinical and nonclinical samples.

Similar to others (Bennett \& Stevens, 1997; Welch, et al., 1988), two conceptually meaningful factors composed of items from multiple subscales were found in the current analysis. This is not surprising, because the high degree of intercorrelation among the original EDI subscales would suggest some degree of overlap in the constructs (Garner et al., 1983). The first, weight concerns, focused on the desire to be thinner and dissatisfaction with body parts. Our data, together with earlier nonclinical studies, provide evidence that the specific eating disorder symptom factors found in clinical samples (drive for thinness, bulimia, body dissastifaction) tend to collapse into one global factor for our nonclinical sample of adolescent girls. Future research might investigate the predictive validity of this

Table 4. Estimates of internal consistency for original EDI subscales for white and black girls (cronbach alphas)

\begin{tabular}{lcr}
\hline EDI Original Subscale & White Girls & Black Girls \\
\hline Drive for Thinness & .88 & .80 \\
Bulimia & .76 & .74 \\
Body Dissatisfaction & .91 & .85 \\
Ineffectiveness & .74 & .65 \\
Perfectionism & .52 & .53 \\
Interpersonal Distrust & .65 & .50 \\
Interoceptive Awareness & .80 & .72 \\
Maturity Fears & .60 & .53 \\
\hline
\end{tabular}

Note: EDI = Eating Disorder Inventory. 
EDI factor as a measure of risk for disordered eating and frank eating disorders in adolescent samples.

Bennett and Stevens (1997) found a factor that included items from all EDI subscales (except BD) that accounted for $34 \%$ of the variance and was called psychological distress. This is similar to our Factor 2 (emotional distress), although it included items from only six of the eight subscales. Thus, two studies have found that the EDI measures a general construct related to emotional states, distress, and low self-esteem, suggesting that the EDI may be measuring a broader psychological construct related to negative affect and psychological distress. The finding of a more global distress factor is consistent with reports of considerable comorbidity found in eating-disordered samples (Bulik, 2002).

The high estimates of internal consistency for both Black and White girls on the Bulimia subscale, which comprises six of the original seven items, are noteworthy for several reasons. Recent interest in binge eating in adolescents has raised questions as to relevant risk factors as well as the natural course of this behavior. It would be of interest to examine whether high scores obtained in early adolescence on the Bulimia subscale predict the onset of binge eating, and perhaps obesity, in later years, particularly in ethnic minority groups (Striegel-Moore et al., 2000; Striegel-Moore, Wilfley, Pike, Dohm, \& Fairburn, 2000).

The two unique factors found in this study (e.g., perfectionism for White girls, body satisfaction for Black girls) may be related to the documented differences in risk factors for eating disorders between Black and White girls (Franko \& Striegel-Moore, 2002). Only the EDI scores of White girls loaded onto a perfectionism factor, suggesting that this may not be a coherent construct for Black girls at this age. The responses of Black girls, but not White girls, loaded onto a factor that contained five of the eight BD subscale items. Because these five items were all positively worded, it appears that the Black girls were actually reporting body satisfaction, rather than dissatisfaction. Alternatively, this may suggest a response set more common among Black girls. The combination of perfectionism and sociocultural emphasis on thinness may predispose White girls to increased risk for eating disturbances, relative to Black girls. Perfectionism has been shown to be a robust correlate of anorexia nervosa (Halmi et al., 2000) and it would be of interest to see whether scores on the perfectionism factor predict restrictive eating patterns in adolescent girls.

The internal consistencies for several of the new factors were quite good and were similar for Black and White girls, with highest estimates for the two combined-item factors (weight concerns and emotional distress) and the bulimia factor. The factors with the lower Cronbach alpha coefficients may reflect the partitioning of the subscales into fewer items. Lower estimates of internal consistency are found when a scale has only very few items (Kaplan \& Saccuzzo, 1997), as was the case with several of the factors (e.g., the maturity fears factor with only five items and the perfectionism factor with only four items). However, the alpha coefficients were of sufficient magnitude to suggest that items on the first three factors (weight concerns, emotional distress, and bulimia) and the body satisfaction factor for Black girls represent internally consistent measures of these constructs. One caveat of note is that combining items into these new factors may weaken the internal consistency of the remaining subscales.

It is of interest that the internal consistency of the eight subscales corresponding to the original EDI was quite favorable for most subscales. In some cases, the estimates were higher than those found for the new factor structure (e.g., the MF subscale). This indicates that this version of the EDI-C can be used in young adolescent girls without hesitation to assess the domains as originally designed by Garner et al. (1983). Our factor analysis suggests that the instrument can also be used to assess additional constructs of 
interest (e.g., weight concerns, emotional distress) that can be created by combining items from several subscales, but does not suggest that the original subscales should not be used with Black and White adolescent samples.

Results of the factor analysis suggest that whether the original subscales or the new factors are used may depend on the research question of interest. There may be significant value in using the new factors found in the current study, particularly for questions related to adolescent risk for eating disorders or body image in Black adolescent girls. However, in using the new subscales, researchers should be aware that the reliability estimates may be low for the remaining subscales. Whether the original eight subscales or the new factors are more useful in answering questions related to the ability to predict the onset of eating disorders awaits empirical study.

The strengths of the study lie in the use of a large geographically diverse community sample, which increases the generalizability of the results. The inclusion of a group of Black adolescent girls is unique to the literature on the psychometric properties of the EDI. Several limitations should also be noted. Because the EDI was not derived from or intended for use with either children or nonclinical samples, caution should be used in the interpretation of these findings. In addition, because a number of the items were reworded for use with a young sample, comparisons to the original EDI should be made judiciously.

The version of the EDI-C used in the current study appears to be a useful instrument for assessing risk for eating disorders in community samples of young Black and White adolescent girls. Our data provide future investigators with psychometric information on a preliminary version of the EDI-C for both White and Black girls. Our results indicate some overlap with the original eight subscales of the EDI. However, there were sufficient differences based on ethnicity to suggest that an alternative set of factors might best be utilized when working with diverse ethnic groups. We found several interesting factors that suggest there are different ways to use the EDI. It is also clear that the original subscales of the EDI work well in this population. Future research might examine the extent to which high scores on these new factors indicate clinically significant eating pathology. Finally, we suggest similar factor analytic studies of the EDI-C be conducted with additional ethnic groups (e.g., Hispanics, Asians) to better understand the similarities and differences in factor structure across diverse populations.

This work was supported by grants from the National Institute of Mental Health and the National Institute of Diabetes, Digestive and Kidney Diseases (R01-MH-64022-01, R01-MH-57897-01). Also supported by contracts HC55023-26 and Cooperative Agreements U01-HL-48941-44 from the National Heart, Lung, and Blood Institute (NHLBI) of the National Institutes of Health. Participating National Growth and Health Study Centers included Children's Medical Center, Cincinnati, Ohio (Stephen R. Daniels, M.D., Principal Investigator, Johan A. Morrison, Ph.D., Co-Investigator); Westat, Inc., Rockville, Maryland (George B. Schreiber, Sc.D., Principal Investigator, Ruth Striegel-Moore, Ph.D., Co-Investigator), and University of California at Berkeley, Berkeley, California (Zak I. Sabry, Ph.D., Principal Investigator, Patricia B. Crawford, Dr.P.H., R.D., Co-Investigator). Maryland Medical Research Institute, Baltimore, Maryland (Bruce A. Barton, Ph.D., Principal Investigator), served as the data coordinating center. Program office: NHLBI (Eva Obarzanek, Ph.D., R.D., Project Office 1992 to present, Gerald H. Payne, M.D., Project Officer 1985-1991).

\section{REFERENCES}

Abrams, K.K., Allen, L.R., \& Gray, J.J. (1993). Disordered eating attitudes and behaviors, psychological adjustment, and ethnic identity: A comparison of black and white female college students. International Journal of Eating Disorders, 14, 49-57. 
Al-Subaie, A.S. (2000). Some correlates of dieting behavior in Saudi schoolgirls. International Journal of Eating Disorders, 28, 242-246.

Bennett, K., \& Stevens, R. (1997). The internal structure of the Eating Disorder Inventory. Health Care for Women International, 18, 495-504.

Boyadjieva, S., \& Steinhausen, H.C. (1996). The Eating Attitudes Test and the Eating Disorders Inventory in four Bulgarian clinical and nonclinical samples. International Journal of Eating Disorders, 19, 93-98.

Bulik, C.M. (2002). Anxiety, depression, and eating disorders. In C.G. Fairburn \& K.D. Brownell (Eds.), Eating disorders and obesity: A comprehensive handbook, (pp. 193-198). New York: Guilford Press.

Cronbach, L.J. (1951). Coefficient alpha and the internal structure of tests. Psychometrika, 16, $297-334$.

Eberenz, K.P., \& Gleaves, D.H. (1994). An examination of the internal consistency and factor structure of the Eating Disorder Inventory-2 in a clinical sample. International Journal of Eating Disorders, 16(4), 371-379.

Engelsen, B.K., \& Laberg, J.C. (2001). A comparison of three questionnaires (EAT-12, EDI, and EDE-Q) for assessment of eating problems in healthy females adolescents. Nordic Journal of Psychiatry, 55, 129-135.

Franko, D.L., \& Streigel-Moore, R.H. (2002). The role of body dissatisfaction as a risk factor for depression in adolescent girls: Are the differences black and white? Journal of Psychosomatic Research, 53, 1-9.

Garner, D.M. (1991). Eating Disorder Inventory- 2 professional manual. Odessa, FL: Psychological Assessment Resources.

Garner, D.M., Olmsted, M.P., \& Polivy, J. (1983). Development and validation of a multidimensional eating disorder inventory for anorexia nervosa and bulimia. International Journal of Eating Disorders, 2, 15-34.

Halmi, K.A., Sunday, S.R., Strober, M., Kaplan, A., Woodside, D.B., Fichter, M., Treasure, J., Berrettini, W.H., \& Kaye, W.H. (2000). Perfectionism in anorexia nervosa: Variation by clinical subtype, obsessionality, and pathological eating behavior. Amrican Journal of Psychiatry, 157, 1799-1805.

Harris, S.M. (1995). Family, self, and sociocultural contributions to body-image attitudes of African-American women. Psychology of Women Quarterly, 19(1), 129-145.

Hatcher, L. (1994). A step-by-step approach to using the SAS system for factor analysis and structural equation modeling. Cary, NC: SAS Institute.

Joiner, T.E., \& Heatherton, T.F. (1998). First- and second-order factor structure of five subscales of the Eating Disorder Inventory. International Journal of Eating Disorders, 23, 189-198.

Kaplan, R.M., \& Saccuzzo, D.P. (1997). Psychological testing: Principles, applications, and issues (4th ed.). Pacific Grove, CA: Brooks/Cole.

Leung, F., Wang, J., \& Tang, C.W. (in press). Psychometric properties and normative data of the Eating Disorder Inventory among Chinese adolescent girls in Hong Kong. International Journal of Eating Disorders.

Morande, G., Celada, J., \& Casas, J.J. (1999). Prevalence of eating disorders in a Spanish school-age population. Journal of Adolescent Health, 24, 212-219.

National Heart, Lung, and Blood Institute Growth and Health Study Research Group (1992). Obesity and cardiovascular disease risk factors in black and white girls: The NHLBI Growth and Health Study. American Journal of Public Health, 82, 1613-1621.

Ohring, R., Graber, J.A., \& Brooks-Gunn, J. (2002). Girls' recurrent and concurrent body dissatisfaction: Correlates and consequences over 8 years. International Journal of Eaing Disorders, 31, 404-415.

Phelps, L., \& Wilczenski, F. (1993). Eating Disorders Inventory-2: Cognitive-behavioral dimensions with nonclinical adolescents. Journal of Clinical Psychology, 49, 508-515.

Raciti, M.C., \& Norcross, J.C. (1987). The EAT and the EDI: Screening, interrelationships, and psychometrics. International Journal of Eating Disorders, 6, 579-586.

Rhea, D.J. (1999). Eating disorder behaviors of ethnically diverse urban female adolescent athletes and nonathletes. Journal of Adolescence, 22, 379-388.

Schaefer, W., Maclennan, R., Yaholnitsky-Smith, S.A., \& Stover, E.D. (1998). Psychometric evaluation of the Eating Disorder Inventory (EDI) in a clinical group. Psychology \& Health, 13(5), 873-881.

Shore, R.A., \& Porter, J.E. (1990). Normative and reliability data for 11 to 18 year olds on the Eating Disorder Inventory. International Journal of Eating Disorders, 9, 201-207.

Simmons, J.R., Smith, G.T., \& Hill, K.K. (2002). Validation of eating and dieting expectancy measures in two adolescent samples. International Journal of Eating Disorders, 31, 461-473.

Smolak, L., \& Striegel-Moore, R.H. (2001). Challenging the myth of the golden girl: Ethnicity and eating disorders. In R.H. Striegel-Moore \& L. Smolak (Eds.), Eating disorders: Innovative directions for research and practice, (pp. 111-132). Washington, DC: American Psychological Association.

Striegel-Moore, R.H., Schreiber, G.B., Lo, A., Crawford, P., Obarzanek, E., \& Rodin, J. (2000). Eating disorder symptoms in a cohort of 11 to 16-year-old black and white girls: The NHLBI growth and health study. International Journal of Eating Disorders, 27, 49-66.

Striegel-Moore, R.H., Wilfley, D.E., Pike, K.M., Dohm, F.A., \& Fairburn, C.G. (2000). Recurrent binge eating in black American women. Archives of Family Medicine, 9, 83-87.

Tsai, G.., \& Gray, J. (2000). Eating Disorders Inventory among Asian American college women. The Journal of Social Psychology, 140(4), 527-529.

Welch, G., Hall, A., \& Walkey, F.H. (1988). The factor structure of the Eating Disorder Inventory. Journal of Clinical Psychology, 44, 51-56. 